\title{
Water infiltration in an aquifer recharge basin affected by temperature and air entrapment
}

\author{
Sébastien Loizeau ${ }^{1,2}$, Yvan Rossier ${ }^{1}$, Jean-Paul Gaudet ${ }^{1}$, Aurore Refloch ${ }^{1}$, Katia Besnard ${ }^{2}$, \\ Rafael Angulo-Jaramillo ${ }^{3}$, Laurent Lassabatere ${ }^{3 *}$ \\ ${ }^{1}$ Université de Grenoble, LTHE UMR5564 Laboratoire d'étude des Transferts en Hydrologie et Environnement, Grenoble 1, CNRS, IRD, \\ Grenoble-INP, BP53 38041 Grenoble Cedex 09, France. \\ ${ }^{2}$ Veolia Environnement Recherche et Innovation, 10 rue Jacques Daguerre, 92500 Rueil-Malmaison, France. \\ ${ }^{3}$ Université de Lyon, LEHNA UMR5023 Laboratoire d'Ecologie des Hydrosystèmes Naturels et Anthropisés, Université Lyon 1, ENTPE, \\ CNRS, INRA, Campus de Vaulx-en-Velin, 3 rue Maurice Audin, 69518 Vaulx-en-Velin, France. \\ ${ }^{*}$ Corresponding author. Tel.: +33 6718387 21. E-mail: laurent.lassabatere@entpe.fr
}

\begin{abstract}
Artificial basins are used to recharge groundwater and protect water pumping fields. In these basins, infiltration rates are monitored to detect any decrease in water infiltration in relation with clogging. However, miss-estimations of infiltration rate may result from neglecting the effects of water temperature change and air-entrapment. This study aims to investigate the effect of temperature and air entrapment on water infiltration at the basin scale by conducting successive infiltration cycles in an experimental basin of $11869 \mathrm{~m}^{2}$ in a pumping field at Crepieux-Charmy (Lyon, France). A first experiment, conducted in summer 2011, showed a strong increase in infiltration rate; which was linked to a potential increase in ground water temperature or a potential dissolution of air entrapped at the beginning of the infiltration. A second experiment was conducted in summer, to inject cold water instead of warm water, and also revealed an increase in infiltration rate. This increase was linked to air dissolution in the soil. A final experiment was conducted in spring with no temperature contrast and no entrapped air (soil initially water-saturated), revealing a constant infiltration rate. Modeling and analysis of experiments revealed that air entrapment and cold water temperature in the soil could substantially reduce infiltration rate over the first infiltration cycles, with respective effects of similar magnitude. Clearly, both water temperature change and air entrapment must be considered for an accurate assessment of the infiltration rate in basins.
\end{abstract}

Keywords: Aquifer recharge; Unsaturated/saturated modeling; Infiltration test; Air entrapment; Temperature dependence.

\section{INTRODUCTION}

Assessing and predicting spatial and temporal fluctuations in aquifer levels and different water fluxes due to recharging are of prime importance for managing water resources (Rai and Singh, 1985). Artificial recharge systems are now commonly used to increase or maintain aquifer water levels (Al-Muttair and Al-Turbak, 1991). Infiltration basins are commonly used to recharge groundwater by infiltrating surface water from rivers or lakes. Additionally, these techniques can help to manage the quality of water supply. For instance, in the region of Lyon (France), a set of infiltration basins were designed to infiltrate surface water in order to maintain a hydraulic mound between the Rhone river arms and the water supply pumping sites. The purpose of this water table mound was to protect the well field from potential nearby river pollution (Fig. 1).

The operation of infiltration basin may be disturbed by several factors like clogging, air entrapment or time evolution of temperature of water at the surface and in the soil profile. Clogging was one of the first factors to be evidenced and studied (Bouwer, 2002). The effect of clogging on water infiltration may be dramatic and endanger the operation of infiltration basins (Gette-Bouvarot et al., 2014; Greskowiak et al., 2005; Kildsgaard and Engesgaard, 2001; Okubo and Matsumoto, 1979; Schuh, 1990, 1988; Tu et al., 2011). To prevent clogging, practitioners usually embed a top layer of sand in infiltration basins and replace it from time to time when the sand gets clogged (Bouwer, 1999). Ongoing research also focuses on the development of ecology engineering for reducing clogging and maintaining infiltration capacity of the systems (Gette-Bouvarot et al., 2014).
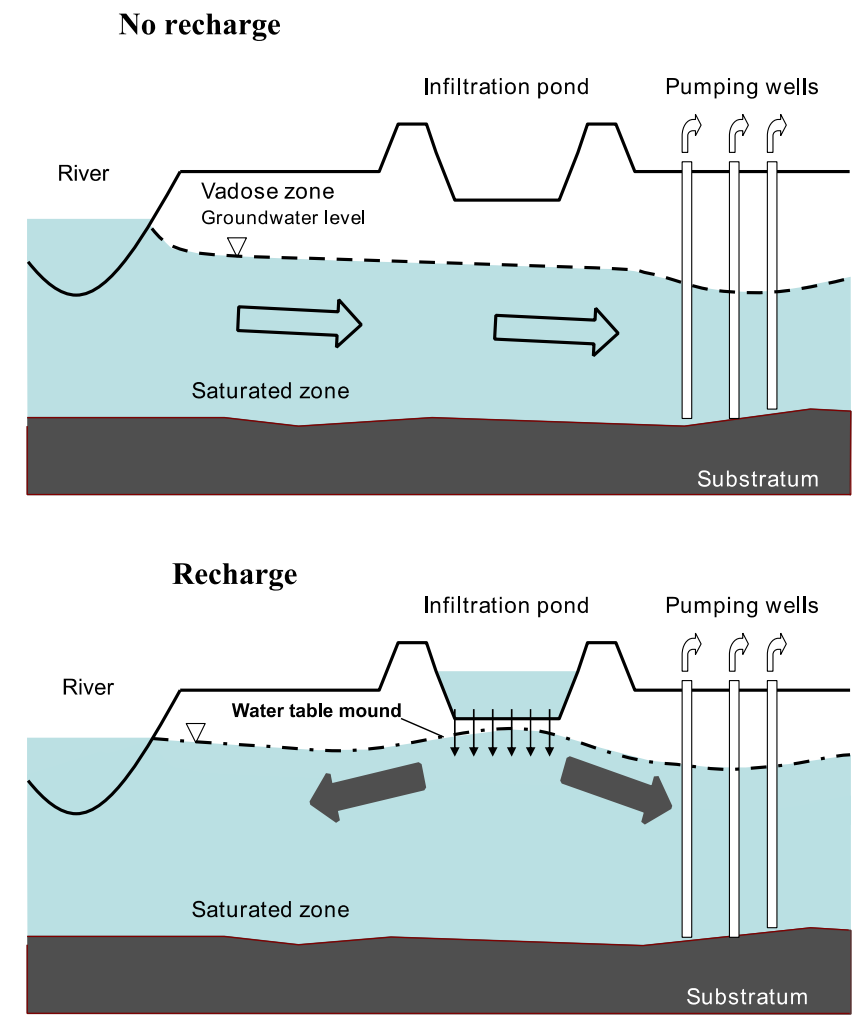

Fig. 1. Artificial recharge and flow under infiltration basins in the study area. 
Water temperature can impact water properties and mostly viscosity, which, in turns impacts soil saturated hydraulic conductivity (Jaynes, 1990) and unsaturated hydraulic conductivity (Constantz, 1982). The effect can be even much more complex than expected since the change in water properties may impact flow pathways at the pore scale and thus modify the effective hydraulic conductivity in a different way than expected when considering only the viscosity-temperature relationship (Constantz, 1982; Constantz et al., 1994). This effect of temperature was clearly established on the field. Vandenbohede and Van Houtte (2012) observed that colder temperatures during winter could result in a decrease of infiltration capacity in surface ponds, by a factor of 1.5 to 2 in comparison with summer periods. Jaynes (1990) noticed in field experiments that water infiltration could vary throughout the day due to changes in surface water temperature. But under some circumstances, the effect of temperature was insufficient to explain time evolution of water infiltration, and air entrapment was identified as a potential additional contributor (Heilweil et al., 2009; Lin et al., 2003).

Entrapped air causes hydraulic conductivity to decrease as a result of reduction in pore space available for water flow (Seymour, 2000). During infiltration, water may block air into the largest pores and isolate air bubbles from the atmosphere (Dohnal et al., 2013; Sněhota et al., 2010). Flow pathways are then excluded from the pores occupied by air bubbles until they have totally dissolved into the interstitial water (Wangemann et al., 2000). Afterwards, the pores become unblocked, and the hydraulic conductivity recovers. Under certain circumstances, the dimensions of air bubbles may be quite important, rendering the process of air dissolution very long and the recovery of hydraulic conductivity quite impossible. For instance, Michot et al. (2003) evidenced the formation of long-term pockets of air within plant root systems with dimensions in the order of dozens of centimeters, in cropped soils submitted to irrigation. In any case, entrapped air in soils is one of the key factors controlling the hydraulic behavior under conditions of ponded infiltration, in perched waters, and in unconfined aquifers (Faybishenko, 1995).

This study aims at investigating experimentally the effects of temperature and air entrapment on water infiltration at the scale of infiltration basins, the effects of clogging having already been investigated (Gette-Bouvarot et al., 2014). Water infiltration experiments were performed in one of the infiltration basins of the water supply pumping site of Crépieux-Charmy that provides Lyon with drinking water. Each water infiltration experiment was composed of several cycles of filling / emptying phases to maintain the water level between thresholds. Three infiltration experiments were performed successively at different periods of the year and with different initial conditions: (1) summer 2011 characterized by the injection of warm surface water in a basin initially dry, (2) winter 2011-2012 with the injection of cold surface water in a basin initially dry, and (3) spring 2012 with the injection of temperate surface water in a basin initially wet. It is expected that the basin response will drastically depend on the contrast in temperature between surface water and groundwater, on the one hand, and on the potential for air entrapment induced by very dry initial states, on the other hand. The level of water in the basin and the temperatures of surface water and groundwater (using a nearby piezometer) were monitored and analyzed to identify infiltration processes in these contrasting situations. Observed water levels were modeled using Richard's equation to derive soil effective saturated hydraulic conductivity, considering this parameter as constant or variable during the infiltration. Time evolution of the derived soil effective hydraulic conductivity was linked to what it should have been with the sole effect of temperature (temperature-viscosity correction) to distinguish the contributions of air entrapment and change in water temperature in the soil profile.

\section{MATERIALS AND METHODS Site description}

In Lyon agglomeration (France), drinking water comes from a main well field located in a highly productive unconfined alluvial aquifer: Crépieux-Charmy (Lyon suburb, France). The aquifer is about $20 \mathrm{~m}$ thick, and composed of sand lenses and gravel layers. The substratum is well delimited by a low permeable sandy-clay layer dating from the Miocene age. More than one hundred pumping wells cover 375 ha over two islands formed by the Rhône river arms. As in most alluvial systems, groundwater quality is strongly related to water exchanges between river and water table. In order to protect fresh water supply wells from river pollution, 12 infiltration basins have been constructed to create an aquifer mound acting as a hydraulic barrier (Fig. 2). The water table mound is created to reverse incoming river flows. In addition to being a protecting barrier, the basins allow the recharge of groundwater, maintaining the water table at a sufficient level for a proper functioning of pumping wells.

The infiltration basin design dates from the early 1990's, and resulted in a $3 \mathrm{~m}$ deep excavation in the alluvial deposit. Infiltration basins have more than 1 ha area and are located close to pumping wells. The bottom of each basin was covered with a layer (between 20 and $30 \mathrm{~cm}$ thick) of calibrated sand to filter mineral and biotic particles and prevent soil from clogging. This sand can be tilled or even replaced when necessary, i.e. in case of significant clogging. Basin operations are controlled by the regulation of water level within maximum and minimum thresholds. The maximum water level in the pond is usually set at $1.80 \mathrm{~m}$ and the minimum can be as low as zero (no water at surface). Supplied water is pumped upstream from the VieuxRhône River, where water quality is continuously monitored with regards to chemical and physical properties. The supplied water has no prior treatment or filtration. In case of high turbidity, water pumping from Vieux-Rhône River and basin recharge are instantaneously interrupted to avoid clogging. The studied basin, referred to as 3.1, is located between the well field and the rivers (Fig. 1). This basin is rectangular, $83 \mathrm{~m}$ wide and $143 \mathrm{~m}$ long for a total surface area $(\mathrm{Sb})$ of $11869 \mathrm{~m}^{2}$. The calibrated sand layer was cleaned during the summer 2010, i.e. about one year before the first infiltration experiment.

\section{Soil profile description}

Basin 3.1 has been embanked in upper alluvium layers with hydraulic characteristics that contrast with the layers underneath. Three trenches each $1.5 \mathrm{~m}$ in depth (G1, G2, G3), were realized in the basin using a mechanic shovel to study the local lithological properties of the soil below. One trench was located in the middle of the basin and the two others $50 \mathrm{~m}$ close to the basin edges to get information on the spatial variability of lithology. For each trench, a lithological description of the soil profile was conducted on the basis of particle size analysis and visual observations. On this basis, three main soil layers were distinguished (Fig. 3a):

(i) layer A; a calibrated homogeneous sand, set up to a depth of $20 \mathrm{~cm}$ to ensure water filtering, (ii) layer B; a heterogeneous sandy gravel (or silty gravel), between 20 to $95 \mathrm{~cm}$ in depth, with a matrix mainly composed of fine sand and silt, and 

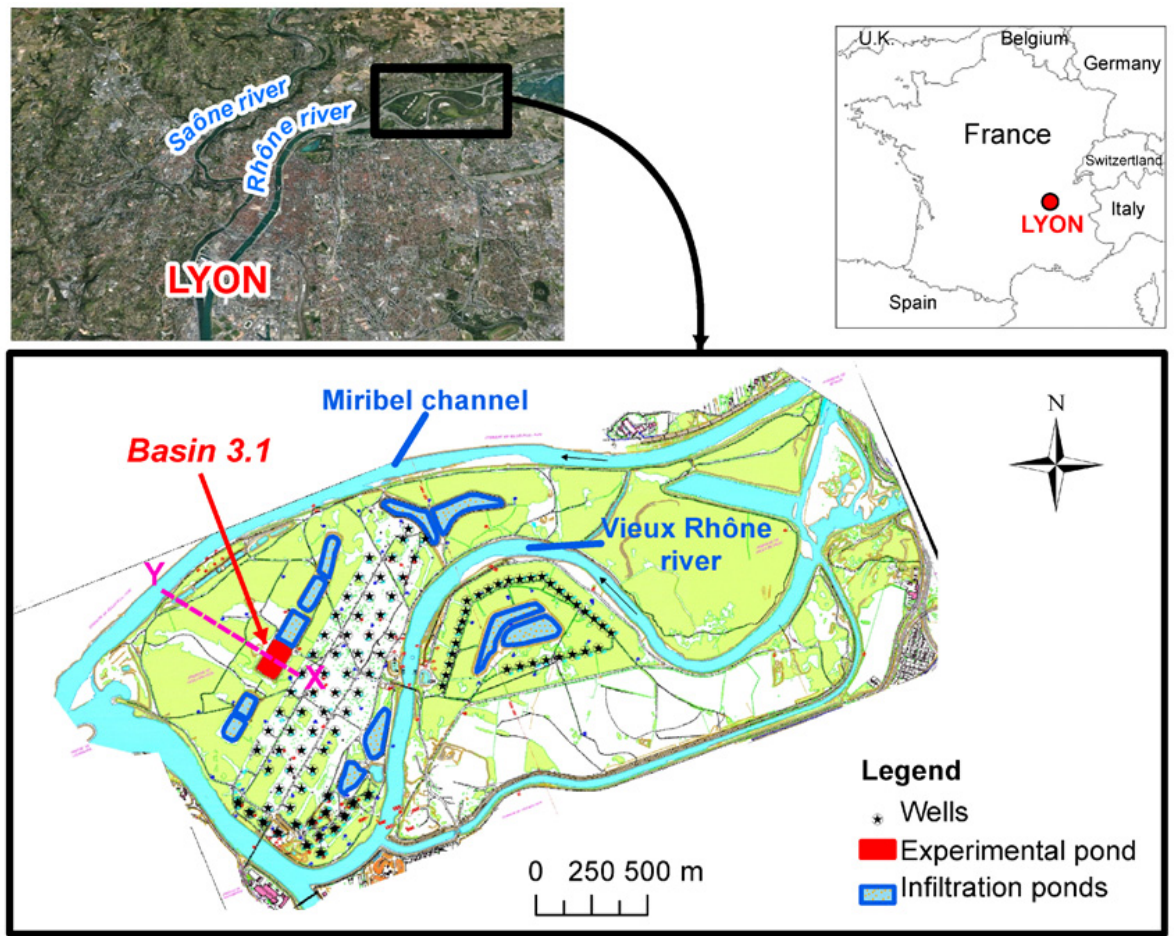

Fig. 2. Location of study area.

a)

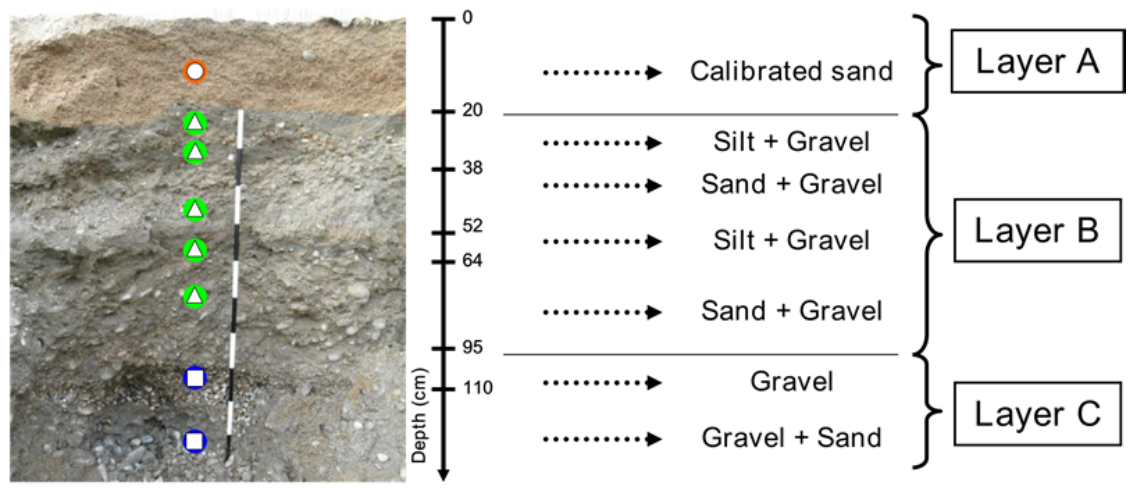

b)

FF $(\%)$

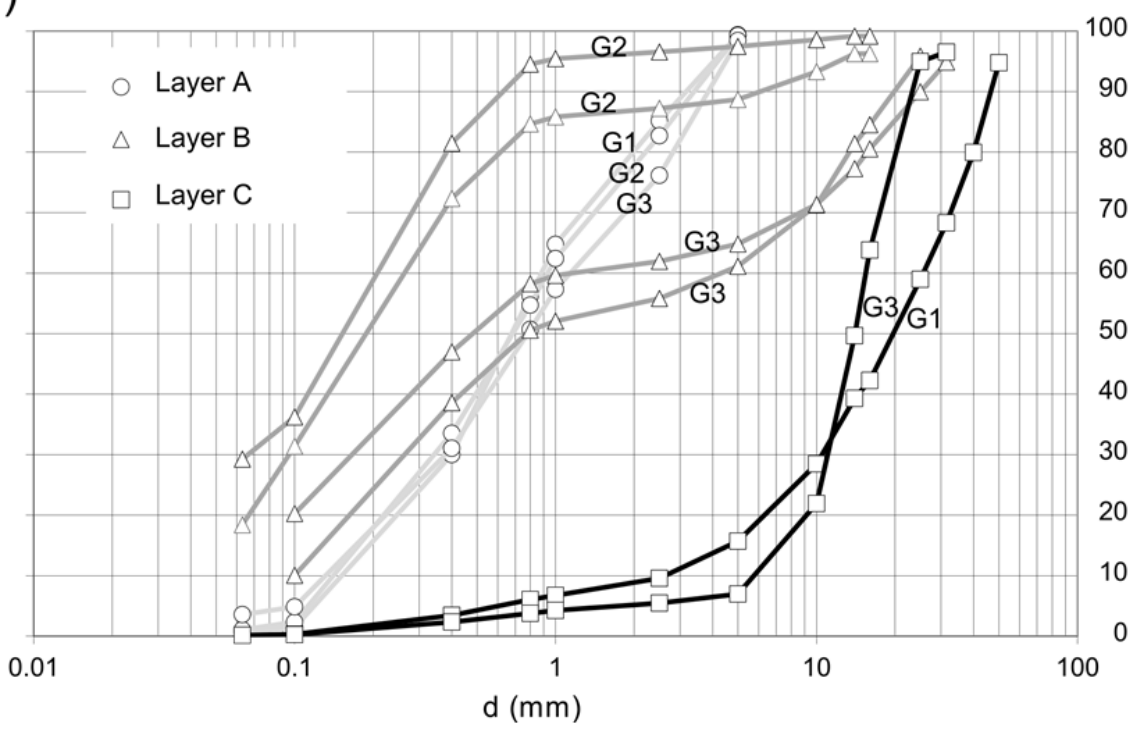

Fig. 3. Soil profile under the basin (a) and particle size analysis (b). 
Water infiltration in an aquifer recharge basin affected by temperature and air entrapment

(iii) layer C; located at a depth of below $95 \mathrm{~cm}$, made of a mixture of gravel and gravelly sand. This last layer constitutes the body of the whole aquifer between layer B and the substratum. The particle size distribution curves are depicted for all trenches and for all layers in Fig. 3b. The curves show no variability between the three profiles (G1, G2, G3) and are relatively narrow with a uniformity coefficient (UC) between 2 and 4. Particle size distribution of layer $\mathrm{B}$ is characterized by a higher spatial variability (Fig. 3b). In addition, its thickness varies from $0.4 \mathrm{~m}$ to $1 \mathrm{~m}$ over the basin area, but an averaged thickness of $1 \mathrm{~m}$ was considered in this study. Layer $\mathrm{C}$ seems more homogenous, but we can notice an increase in gravel size up to a depth of $1 \mathrm{~m}$.

\section{INFILTRATION TESTS: EXPERIMENTS AND MODELING Infiltration experiments}

For all experiments, the water level was measured continuously in the basin. The supplied water flow rate is monitored with a flow meter. During the phase of filling, basin water level increases up to the maximum level allowed and then water supply is stopped. Then water level progressively decreases as the result of water infiltration (basin emptying). When the minimum threshold $(1.80 \mathrm{~m})$ is reached, the water supply is reactivated. Basin water level fluctuates between the maximum and minimum thresholds designed for the specific case of infiltration experiments. Supplied water and aquifer temperatures are continuously measured with thermal loggers in the basin and in a piezometer located nearby. The maximum aquifer level is also measured to check that it remains $2 \mathrm{~m}$ below the basin surface (prerequisite to ensure that the vadose zone under the basin is at least $2 \mathrm{~m}$ thick). If this condition is not fulfilled, the water supply is stopped.

As explained in the introduction, the infiltration experiments were designed to test three distinct scenarios: (1) infiltration in summer of warm water into the dry soil, (2) infiltration in winter of cold water into the dry soil and finally (3), infiltration of lukewarm water into the wet soil. Dry conditions were ensured by avoiding any water injection for long enough to let water redistribute into the soil profile and water content decrease to values less than field capacity. The first infiltration experiment was conducted in summer 2011. The basin was kept empty for one month before the first injection of water to ensure initial low water contents in the soil. Then, the basin was fed with surface water at a temperature of $24^{\circ} \mathrm{C}$ against $12^{\circ} \mathrm{C}$ for groundwater. Six filling/emptying cycles were applied over 12 days with a constant supply flow rate of $1800 \mathrm{~m}^{3} / \mathrm{h}$. The second series of filling/emptying cycles was conducted during winter 2011-2012. As for the first experiment, the basin was kept empty for one month before the experiments. The basin was then fed with four cycles of filling/emptying over eight days with constant supply flow rates of $1800 \mathrm{~m}^{3} / \mathrm{h}$. The surface water temperature was around $11^{\circ} \mathrm{C}$ against $15^{\circ} \mathrm{C}$ for groundwater. The last infiltration experiment was carried out in spring 2012, and the basin was maintained filled throughout several days before the experiment to ensure an initial state close to water saturation. The recharge operation included 20 cycles over eight days with an imposed average filling flow rate of 2600 $\mathrm{m}^{3} / \mathrm{h}$. The average temperature was $15^{\circ} \mathrm{C}$ for surface water against $12^{\circ} \mathrm{C}$ for groundwater. For the estimation of initial water contents, layers A and B were sampled for the two first experiments. For the last experiment, the soil was considered quasi-saturated, and its initial volumetric water content was equaled to its bulk porosity. For all infiltration experiments and each filling/emptying cycle, infiltration rates (IR) were determined by dividing the decrease in water level by the duration of the emptying phase.

\section{Modeling: flow equations and soil hydraulic properties}

Unsaturated and saturated water flow was simulated by solving 2D Richards' equation (Richards, 1931):

$$
\frac{\partial \theta(h)}{\partial t}=\frac{\partial}{\partial x}\left[K(h) \frac{\partial h}{\partial x}\right]+\frac{\partial}{\partial z}\left[K(h)\left(1+\frac{\partial h}{\partial z}\right)\right]
$$

where, $\theta(h)$ is the volumetric water retention curve, $K(\theta)$ is the tensor of hydraulic conductivity $[\mathrm{m} / \mathrm{s}]$ considered here as isotropic and depending on water pressure head $h[\mathrm{~m}], x, y$, and $z$ are space coordinates $[\mathrm{m}]$ and $t$ is time [s]. Water retention curve is described by van Genuchten (1980) relationship along with Mualem (1976) condition:

$$
\begin{aligned}
& S_{e}=\frac{\left(\theta-\theta_{r}\right)}{\left(\theta_{s}-\theta_{r}\right)} \\
& S_{e}(h)=\left(1+(\alpha h)^{n}\right)^{-m}
\end{aligned}
$$

where $\theta_{s}$ is the saturated volumetric water content $\left[\mathrm{m}^{3} / \mathrm{m}^{3}\right], \theta_{r}$ is the residual volumetric water content $\left[\mathrm{m}^{3} / \mathrm{m}^{3}\right]$ and $S_{e}$ the effective saturation $[-], \alpha$ is a parameter linked to capillary fringe $\left[\mathrm{m}^{-1}\right]$, also considered as a scale parameter for water pressure head, and $\mathrm{m}$ and $\mathrm{n}$, two shape parameters linked by Mualem's restriction: $m=1-1 / n$. In such conditions, hydraulic conductivity curve is defined through the Mualem's capillary model (Mualem, 1976), leading to (Šimůnek et al., 2003):

$$
K(h)=K_{s} S_{e}^{\tau}\left(1-\left(1-S_{e}^{1 / m}\right)^{m}\right)^{2}
$$

where $K_{s}$ is the saturated hydraulic conductivity $[\mathrm{m} / \mathrm{s}]$ and $\tau=$ 0.5 is a constant tortuosity parameter (Mualem, 1976).

The hydraulic parameters of all elementary soil material were determined through specific in-situ water infiltration experiments. For the layer A, single ring infiltration tests $(0.13$ $\mathrm{m}$ in diameter) were performed at zero pressure head according to the so-called "Beerkan method" (Braud et al., 1995). Beerkan infiltration data were interpreted using the "BEST" algorithm (Lassabatere et al., 2006), which derives the entire set of hydraulic parameters through fitting infiltration data on the analytical infiltration model proposed by Haverkamp et al. (1994). This model has been recently validated on generated numerical data (Lassabatere et al., 2009) and field data including coarse materials (Di Prima et al., 2016; Lassabatere et al., 2010; Nasta et al., 2012; Yilmaz et al., 2013, 2010). The mean saturated hydraulic conductivity was $3.5 .10^{-5} \mathrm{~m} / \mathrm{s}$. This value was considered valid for all the scenarios since no significant clogging of sand (i.e. layer A) was observed. With regards to the basin infiltration characteristic time, layer A was supposed to get saturated instantaneously, so in the model layer A could be considered as the upper Cauchy-type boundary condition of the flow domain with a constant hydraulic transfer resistance, $K_{T}$, defined as:

$$
K_{T}=K_{s A} / e
$$

where $K_{S A}$ is the saturated hydraulic conductivity of layer A and $e$ stands for its thickness. 
In the model, Layer B was $1 \mathrm{~m}$ deep. A first estimation of layer B hydrodynamic properties has been performed using a single ring infiltrometer $(1 \mathrm{~m}$ in diameter) (results not presented here, (Loizeau, 2013)). The large dimension of the ring was chosen given the large diameter of certain soil particles. The cumulative infiltration was then inverted numerically to derive first estimates of hydraulic properties of layer B and, in particular, of its saturated hydraulic conductivity. Afterwards, the value of saturated hydraulic conductivity was optimized by fitting water levels for the two first cycles of infiltration experiments. A numerical sensitivity analysis of infiltration showed that layer B saturated hydraulic conductivity was the most sensitive parameter, ensuring the good reliability of its estimates. Its residual water content was fixed at zero, and its saturated water content was derived from its bulk porosity, as estimated from field samples.

For layer C, $13.5 \mathrm{~m}$ thick, its saturated hydraulic conductivity was assigned to average hydraulic conductivity previously obtained with pumping tests. Values ranged between $8.10^{-3} \mathrm{~m} / \mathrm{s}$ and $5.10^{-2} \mathrm{~m} / \mathrm{s}$ (Loizeau, 2013). The effective porosity is related to the drainage volumetric water content corresponding to $\left(\theta_{s}-\right.$ $\theta_{r}$ ). Pore space available for drainage is then $15 \%$ in layer $\mathrm{C}$, estimated by a specific flood wave depreciation experiment (results not presented here, (Loizeau, 2013)). The estimated hydraulic parameters range in order of magnitude as those of previous values proposed by other studies for sedimentary deposits (Goutaland et al., 2013; Stephens et al., 1998). The parameters $\alpha$ and $n$ for layers B and C were fixed in agreement with literature data. All hydraulic parameters are listed in Table 1.

\section{Flow domain, initial and boundary conditions}

River channels and piezometers allow for precise information on water levels and then were used as a source of information for model boundary conditions. The numerical model for 2D modeling was defined as the cross-section view $\mathrm{XY}$ going through Miribel channel (Y) to active pumping wells (X), for which water levels are available. It includes basin 3.1 and its surroundings as depicted in Fig. 2, and includes the entire three layers. The distance from the basin center to the wells location is $141.5 \mathrm{~m}$, and to the river is $557.1 \mathrm{~m}$ (Fig. 4). The basin is $3 \mathrm{~m}$ in depth. The finite element model option available in $\mathrm{COMSOL}^{\circledR} 4.3$ code was used to simulate both unsaturated/saturated transient flow conditions in the flow domain. The spatial mesh was refined within the surroundings of the basin and wells location. Typically, mesh element dimensions ranged between $0.2 \mathrm{~m}$ and $1.5 \mathrm{~m}$ for most elements, except in the refined zone, where they were $4 \mathrm{~cm}$ in width and $40 \mathrm{~cm}$ in length.

The lower boundary was chosen as a null flux condition in relation to the aquifer substratum (Fig. 4). For the right and left boundaries, located at the wells $(\mathrm{X})$ and the channel $(\mathrm{Y})$, we neglected time variation of water table during the experiments. Thus, these boundaries are assigned with the value of pressure head measured at each river location. We considered the values of $165.15 \mathrm{~m}(\mathrm{NGF})$ and $162.3 \mathrm{~m}(\mathrm{NGF})$, respectively for the channel $(\mathrm{Y})$ and the wells $(\mathrm{X})$. For the upper boundary layer, we neglected precipitation and evapotranspiration in comparison with the larger infiltrated volumes. This boundary was zero flux except for the infiltration surface. Basin vertical embankments are considered as impermeable and are therefore assigned a zero flux condition. For the infiltration surface, boundary condition is fixed on the basis of the mass balance between the flux entering the basin, derived from the measure of supplied water flow rate $Q_{(i n)}\left[\mathrm{m}^{3} / \mathrm{s}\right]$, and infiltration rate. Indeed, at each time-step, the numerical resolution of Richards' equation provides the Darcy velocity for each element of the infiltration surface. Surface integration of the local Darcy velocity provides total infiltration flow rate, $Q_{(o u t)}\left[\mathrm{m}^{3} / \mathrm{s}\right]$. The latter is divided by the infiltration surface, $S b$, in order to calculate the flux to be imposed at the boundary: $q_{\text {boundary }}=Q_{(o u t)} / S b$. Then, the time

Table 1. Hydraulic parameters, with layer thickness, e, residual and saturated water contents, $\theta_{r}$ and $\theta_{s}$, respectively, variation of water content $\Delta \theta$, scale parameter for water pressure head, $\alpha$, shape parameter $\mathrm{n}$, and saturated hydraulic conductivity, $K_{s}$.

\begin{tabular}{l|ccccccc}
\hline Layer & $e[\mathrm{~m}]$ & $\theta_{r}\left[\mathrm{~m}^{3} \mathrm{~m}^{-3}\right]$ & $\theta_{s}\left[\mathrm{~m}^{3} \mathrm{~m}^{-3}\right]$ & $\Delta \theta\left[\mathrm{m}^{3} \mathrm{~m}^{-3}\right]$ & $\alpha\left[\mathrm{m}^{-1}\right]$ & $n[-]$ & $K_{s}\left[\mathrm{~m} \mathrm{~s}^{-1}\right]$ \\
\hline A & 0.2 & - & - & - & - & - & $3.5 .10^{-5}$ \\
B & 1 & 0 & 0.2 & 0.2 & 0.8 & 1.8 & $1.12 .10^{-5 *}$ \\
C & 13.5 & 0.15 & 0.3 & 0.15 & 1.2 & 2.5 & $2.10^{-2}$ \\
\hline
\end{tabular}

* estimates from inverse modeling

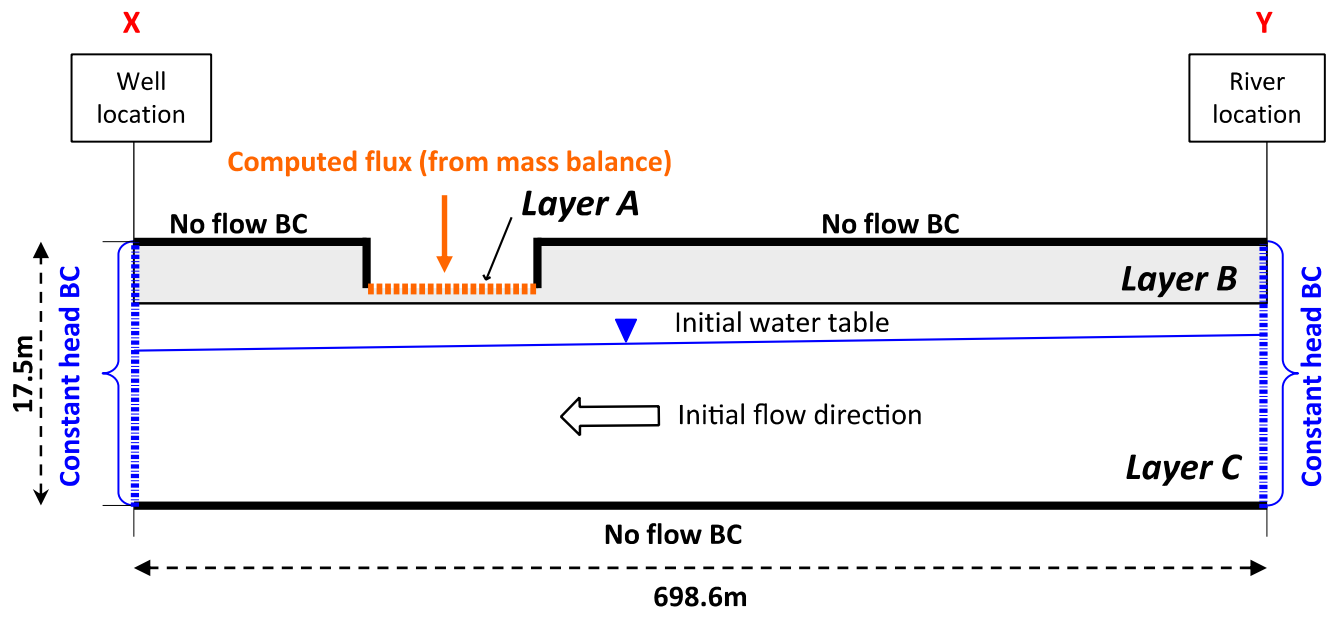

Fig. 4. Cross section $\mathrm{X}-\mathrm{Y}$ location and $2 \mathrm{D}$ view with boundary conditions. 
variation of the water level is computed as the result of the contribution of entering water $\left(Q_{(i n)}\right)$ and total infiltration flow rate $\left(Q_{(o u t)}\right)$ :

$$
\frac{\partial V_{w}}{\partial t}=Q_{(\text {in })}-Q_{(\text {out })}
$$

where $V w$ is the total water volume $\left[\mathrm{m}^{3}\right]$. The water level in the basin corresponds to the volume $V_{w}$ divided by the surface of the infiltration basin, $S b$, and can be compared with measured water levels.

Finally, the initial conditions are: the basin is empty (i.e. $V_{w}$ $=0$ at $t=0$ ) and null water supply (i.e. $Q_{(i n)}=0$ ). Initial water table is calculated with the head boundary condition and equilibrium water pressure head is then derived for the whole domain.

\section{Time evolution of $K_{s}$ for layer B during infiltration experiments.}

As a first approach, air entrapment and temperature changes were supposed to occur mainly in layer B and all effects were lumped into one single parameter, namely the saturated hydraulic conductivity of layer B. This parameter was the single parameter to be optimized by fitting numerically modeled data to observed water levels. The other hydraulic parameters for layers A, B and C were fixed as listed in Table 1.

Two options were considered regarding the value of the saturated hydraulic conductivity of layer B, $K_{s B}$. For the first scenario, $K_{s B}$ was kept constant and fixed at its value previously estimated from infiltrometer experiments (see above) and detailed in Table 1. For the second scenario, $K_{s B}$ was considered to evolve with time as the result of temperature and airentrapment effects. It was even assumed to evolve linearly with infiltration rate at the surface. Cycle-averaged values of $K_{s B}(i)$ were then fixed from the cycle-averaged values of infiltration rates $I R(i)$ as follows:

$$
\begin{aligned}
& K_{s B}(i)=K_{s B 0} f(i) \\
& f(i)=\frac{I R(i)}{I R_{0}}
\end{aligned}
$$

where $K_{S B O}$ is the initial saturated hydraulic conductivity also considered for the first filling/emptying cycle; $f(i)$ is a dimensionless relationship depending on $I R(i)$ and $I R_{0}$ the initial infiltration rate calculated for the first emptying phase.

The time-evolution of $K_{s B}$ was then compared to what it should have been with the sole effect of temperature. The ratio of saturated hydraulic conductivity $K_{S B}(i) / K_{s B O}$ was compared to the ratio of hydraulic conductivity explained only by the variation in temperature and its consequences on water bulk density and dynamic viscosity. Indeed, the saturated hydraulic conductivity inversely changes with fluid dynamic viscosity following the relationship (Muskat, 1937):

$$
K_{S}=\frac{k \rho g}{\mu}
$$

where $k$ is the intrinsic permeability $\left[\mathrm{m}^{-2}\right]$ that doesn't depend on fluid properties, $\rho$ is the fluid density $\left[\mathrm{kg} / \mathrm{m}^{3}\right], g$ is the gravitational acceleration $\left[\mathrm{m} / \mathrm{s}^{2}\right], \mu$ is the water dynamic viscosity [Pa s] and $K_{s}$ is the temperature dependent saturated hydraulic conductivity $[\mathrm{m} / \mathrm{s}]$. The initial and final temperatures of water within the soil profiles were then fixed at the values of groundwater and surface water, as a first approach. The related hydraulic conductivity was then estimated for the final and initial states, considering that groundwater is a good estimate for water temperature in the profile at time zero and that all the water stored in the soil profile has been completely replaced by surface temperature with its own temperature at the end of infiltration experiments. Heat transfer into soils is much more complex, and these latter two hypotheses are over-simplifying. However, heat transfer and its coupling with flow will be investigated in subsequent papers and will not be investigated in any more detail in this study.

\section{RESULTS AND DISCUSSION \\ Water infiltration and time evolution of IR due to tempera- ture change and air entrapment}

The experimental results are depicted in Fig. 5 for water levels and Fig. 6 for water temperatures at the surface and in the groundwater. The first experiment conducted in summer 2011 included 6 cycles over 12 days 2011 after a dry period of one month to ensure a dry initial state (volumetric water content measured at $0.03 \mathrm{~m}^{3} \mathrm{~m}^{-3}$ ). The temperature of surface water was roughly constant around $24^{\circ} \mathrm{C}$ (with variations ranging between $22^{\circ} \mathrm{C}$ and $26^{\circ} \mathrm{C}$ ) versus $12^{\circ} \mathrm{C}$ for groundwater before water infiltration (Fig. 6a, time zero). From day 3 to day 7, the water temperature increased gradually from $12^{\circ} \mathrm{C}$ to $22^{\circ} \mathrm{C}$ in the piezometer M03, revealing that water has warmed up along the whole soil profile and around the infiltration basin within $\sim 5$ days (time of the arrival of warm water at the piezometer). In the basin, the water level oscillates between the two thresholds imposed for this experiment, $2.17 \mathrm{~m}$ and $1.17 \mathrm{~m}$. For the three first cycles, the water level reaches the highest threshold $2.17 \mathrm{~m}$ (Fig. 5, cycles 1, 2 and 3). Conversely, during cycles 4, 5 and 6, the same threshold was never attained due to too high infiltration rates. Since the upper threshold could not be attained, it was decided to stop the filling as soon as the water level stabilized. The measured IR varied from $1.95 \mathrm{~m} / \mathrm{d}$ to a maximum value of $3.48 \mathrm{~m} / \mathrm{d}$ in three cycles, i.e. 6 days, with stabilization of IR afterwards (Fig. 5b). Such increase corresponded to $78 \%$ of the initial value, which is in the same order of that observed by Lin et al. (2003). This could be explained indistinctly from temperature increase of water in the soil profile and subsequent increase in effective hydraulic conductivity or dissolution of air entrapped at the beginning of water injection. Given these results, the second experiment was planned to inject cold water. If viscosity was the sole factor, the injection of cold water should result in a concomitant decrease in hydraulic conductivity and infiltration rate.

The second infiltration experiment was then planned in winter 2011-2012. As for the first infiltration experiment, the basin was kept draining without any entering water (except rainfalls) for one month before the experiments, leading to an initial water content of $0.10 \mathrm{~m}^{3} \mathrm{~m}^{-3}$. The basin was then fed with surface water for four filling/emptying cycles for 8 days. The temperature of surface water remains quite constant around $11^{\circ} \mathrm{C}$ with a small decrease at the end of the experiments. Groundwater temperature also remains constant around $15^{\circ} \mathrm{C}$ with also a tiny decrease after $\sim 5 \mathrm{~d}$ (Fig. $6 \mathrm{~b}$ ). In contrast to the previous experiment (Fig. 6a), the change in temperature in the piezometer is not drastic and there is no alignment of groundwater temperature and the temperature of injected surface water (see Fig. 6b versus Fig. 6a). It seems that the change in temperature in the profile is smoother than for the first experiment. 

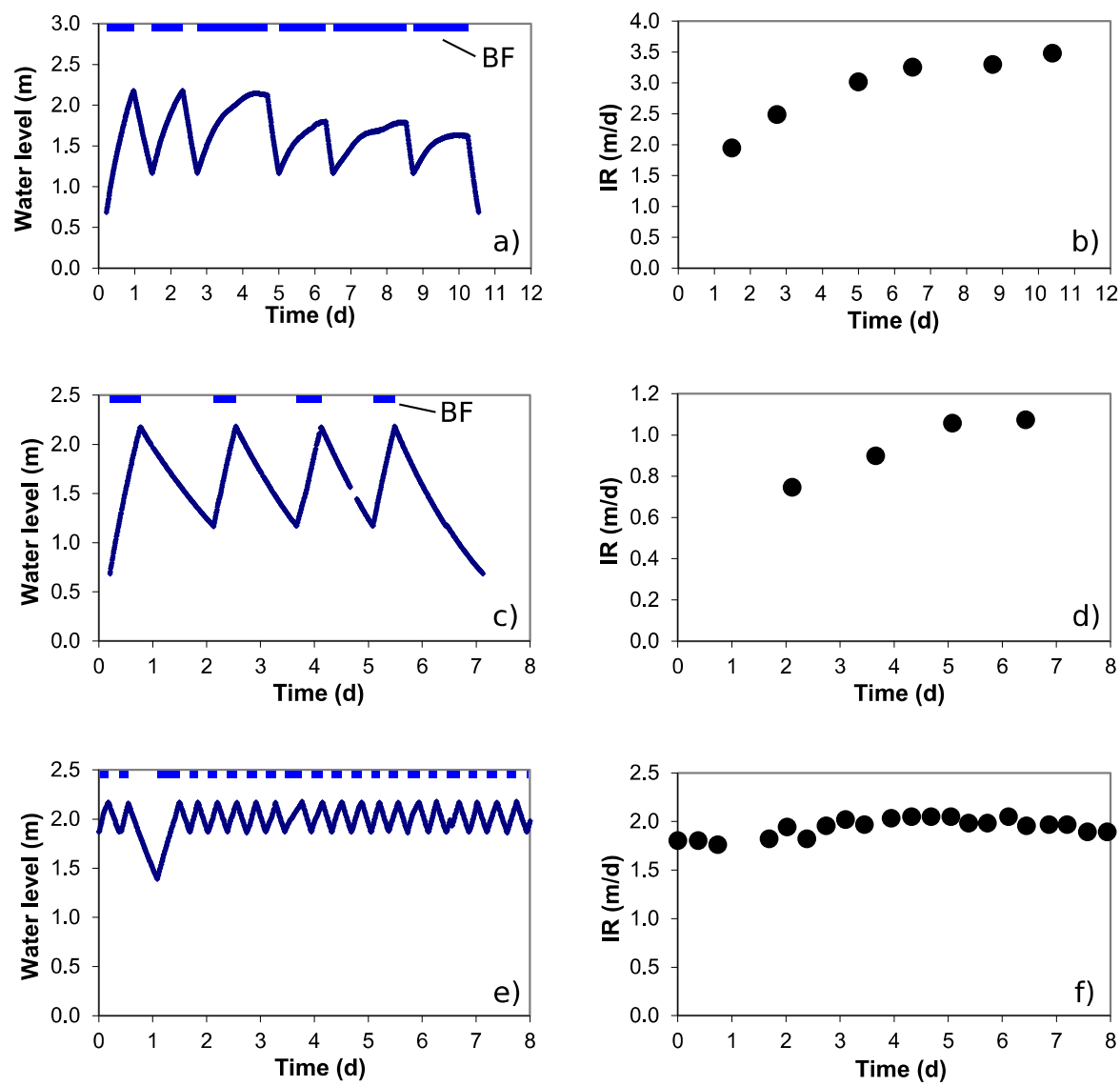

Fig. 5. Water levels and infiltration rate for three infiltration tests performed in the basin 3.1 during a-b) summer 2011, c-d) winter 20112012, e-f) spring 2012, , water levels (right) and infiltration rates (IR) left; basin filling periods (BF) are shown in the pictures.
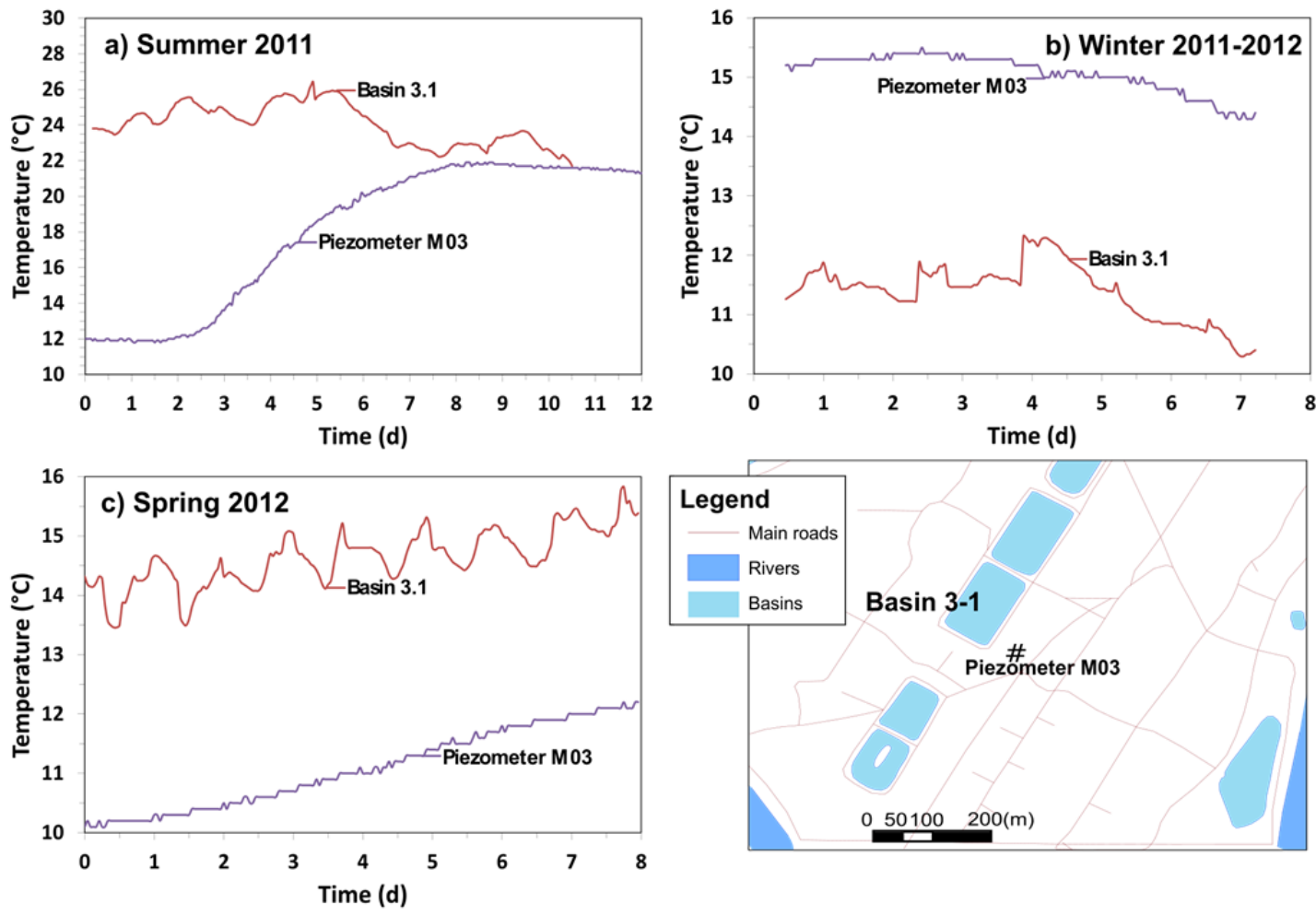

Fig. 6. Water temperature in the basin 3.1 and in the piezometer M03 during the three injection experiments (a-c) and location of the piezometer M03 (d). 
This could result from the lower contrast in temperature with only $4^{\circ} \mathrm{C}$ of difference in winter $2011-2012$ instead of $12^{\circ} \mathrm{C}$ in summer 2011. The imposed maximum and minimum water levels were fixed at $2.17 \mathrm{~m}$ and $1.17 \mathrm{~m}$, respectively, allowing 1 $\mathrm{m}$ of water level variation for emptying steps. In contrast to the first infiltration experiment, water infiltration did not prevent water level reaching the maximum, leading to complete oscillations between $2.17 \mathrm{~m}$ and $1.17 \mathrm{~m}$ (Fig. 5d). The infiltration rate (IR) increased from $0.75 \mathrm{~m} / \mathrm{d}$ to $1.07 \mathrm{~m} / \mathrm{d}$ (Fig. 5d). IR increased mainly before the third cycle and stabilized after 5 days. Such an increase corresponded to $43 \%$ of the initial value. This increase is inconsistent with the hypothesis of the effect of the change in temperature. Indeed, the injection of cold water should have cooled down the temperature in the profile and thus decrease hydraulic conductivity. The observed increase was then attributed to the dissolution of air entrapped at the beginning of the injection. Entrapped air could have slowed down water infiltration during 5 days, before dissolving, leading to the recovery of the infiltration rate. This experiment proves that even without the help of temperature increase (like in summer 2012), a significant increase of IR could be observed as the result of dissolution of air entrapped at the beginning of infiltration cycles.

The last infiltration was designed to confirm the influence of entrapped air by proceeding to water injection in a fully saturated soil at time zero. The experiment was then scheduled in spring 2012, after a long period of water infiltration to ensure an initial state close to saturation. Twenty cycles were carried out with maximum and minimum water levels fixed at $2.17 \mathrm{~m}$ and $1.87 \mathrm{~m}$, respectively (Fig. 5e). The measurement of temperature revealed that there remained a slight difference between the temperature of surface water and groundwater, with respectively $15^{\circ} \mathrm{C}$ and $11^{\circ} \mathrm{C}$ (Fig. 6c). The time evolution of temperature in surface water shows the impact of daily warm up (oscillations with daily periodicity) and the gradual increase of both groundwater and surface water temperature, probably typical for the spring season. As for the previous experiment (Fig. 6b) and in contrast to the first experiment (Fig. 6a), groundwater temperature does not change drastically and does not align to the temperature of injected surface water (see Fig. $6 \mathrm{c})$. The contrast in temperature of only $4^{\circ} \mathrm{C}$ may have been insufficient to warm up water along the soil profile and to allow warm water to reach the piezometer M030. At surface, water level oscillates between the two targeted thresholds of $1.85 \mathrm{~m}$ and $2.15 \mathrm{~m}$. The computation of infiltration rate reveals a constant value of $2 \mathrm{~m} / \mathrm{d}$ for all cycles IR. Clearly, in the absence of temperature effect or entrapped air, infiltration rate remains constant, revealing that there should not be additional factors and that they are the key factors. It becomes clear that the suppression of entrapped air at the beginning of infiltration experiments allows a perfect stability of infiltration rate.

These results show that both entrapped air and temperature effect may play a significant role in water infiltration. However, the effect of temperature was expected only for the first experiments, for which the contrast in temperature was enough to change temperature along the profile around the basin. For the other experiments, the change in temperature may have been tiny. For these, the effect of temperature change is not expected to be important. The effect of entrapped air seemed important for all experiments with the injection of water in the basin initially dry. The following section addresses the numerical modeling the separate effect temperature change and air entrapment on the value of effective hydraulic conductivity of layer B.

\section{Time-evolution of saturated hydraulic conductivity}

As explained in the material and section, all the effects were lumped into one single parameter, namely the saturated hydraulic conductivity of layer B, $K_{s B}$. Modeling the infiltration was performed with two assumptions: no time variation on $K_{s B}$, and time evolution on $K_{s B}(t)$ due to both temperature change and air entrapment. Modeled water levels in the basin are depicted for both cases and for both summers 2011 and winter 2011-2012 (Fig. 7a and b). Water contents below the basin are represented for the case of variable $K_{s B}$ and summer 2011 (Fig. 7c).

Modeling accuracy is illustrated for the infiltration experiment performed in summer 2011 in Fig. 7a. Constant hydraulic conductivity, $K_{s B}=8.810^{-6} \mathrm{~m} / \mathrm{s}$, is derived from fitting the model to the observed values for the first two cycles. After 3 days of recharge, the modeled water levels in the basin are higher than observed values, and the discrepancies between observations and modeled data become significant (Fig. 7a). Thus constant $K_{s B}$ does not allow any accurate fit of the observations. The same scenario was modeled considering the hydraulic conductivity $K_{s B}(i)$ varying with time according to Eqs. (7). The fit becomes very accurate with no discrepancies between modelled and observed data (Fig. 7a). The optimized hydraulic conductivity gradually increased from $8.810^{-6} \mathrm{~m} / \mathrm{s}$ to $1.5610^{-5} \mathrm{~m} / \mathrm{s}$, corresponding to an increase by a factor of 1.79 (Table 2). The model also gives insight on processes below the basin (Fig. 7c). In comparison to the initial state, the injection of water increases water content just below the basin and moistens the whole profile down to the water table. It is clear that the water table rises due to the injection of water (Fig. 7c $t=10 \mathrm{~d}$ versus $t=0 \mathrm{~d}$, white line). Moreover, its shape changes from a linear shape (Fig. 7c $t=0 \mathrm{~d}$ ) to that of a piecewise function with a horizontal line on the right and a tilted line on the left (e.g. Fig. $7 \mathrm{c} t=$ from 2 to $10 \mathrm{~d}$ ). At the end, the water table below the basin and on its right side reaches the level of layer B (Fig. $7 \mathrm{c} t=10 \mathrm{~d}$ ). Modeling proves that the injection of water in the basin clearly creates the mound targeted for protecting the pumping wells.

Table 2. Evolution of ratio of estimated saturated hydraulic conductivity for layer B $K_{s B} / K_{s B 0}$ and expected ratio considering viscosity correction for the two experiments summer 2011 and winter 2011-2012.

\begin{tabular}{cc|cc}
\hline \multicolumn{2}{c|}{ Summer 2011} & \multicolumn{2}{c}{ Winter $2011-2012$} \\
\hline Time $(\mathrm{d})$ & $K_{s B} / K_{s B 0}$ & Time $(\mathrm{d})$ & $K_{s B} / K_{s B 0}$ \\
\hline 1.48 & 1.00 & 2.12 & 1 \\
2.74 & 1.28 & 3.66 & 1.21 \\
5.0 & 1.55 & 5.07 & 1.42 \\
6.5 & 1.67 & 6.43 & 1.44 \\
8.73 & 1.70 & & 0.897 \\
10.4 & 1.79 & & \\
\hline \multicolumn{4}{c}{ Viscosity correction } \\
\hline \multicolumn{4}{c}{1.35} \\
\hline
\end{tabular}

* estimates from inverse modeling

Similar trends were found in the case of winter 2011-2012. None of the constant values for saturated hydraulic conductivity $K_{s B}$ could provide an accurate fit of the observed data, in contrast to the case of $K_{s B}$ as predicted by Eqs. (7) (Fig. 7b). Eqs. (7) predicted a gradual increase in saturated hydraulic conductivity from $3.3710^{-6} \mathrm{~m} / \mathrm{s}$ to $4.8510^{-5} \mathrm{~m} / \mathrm{s}$, corresponding to an increase by a factor 1.44 (Table 2). Modeled water contents showed also the appearance of a mound with a concomitant rise of water table and creation of a bulb below the basin, as for summer 2011 (data not shown). 

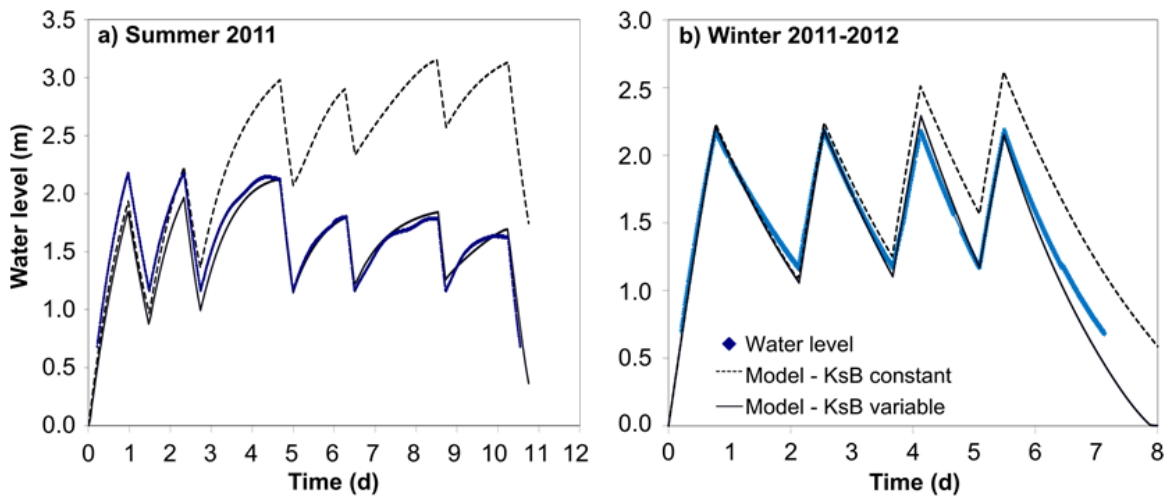

c) Modelled water content Summer 2011
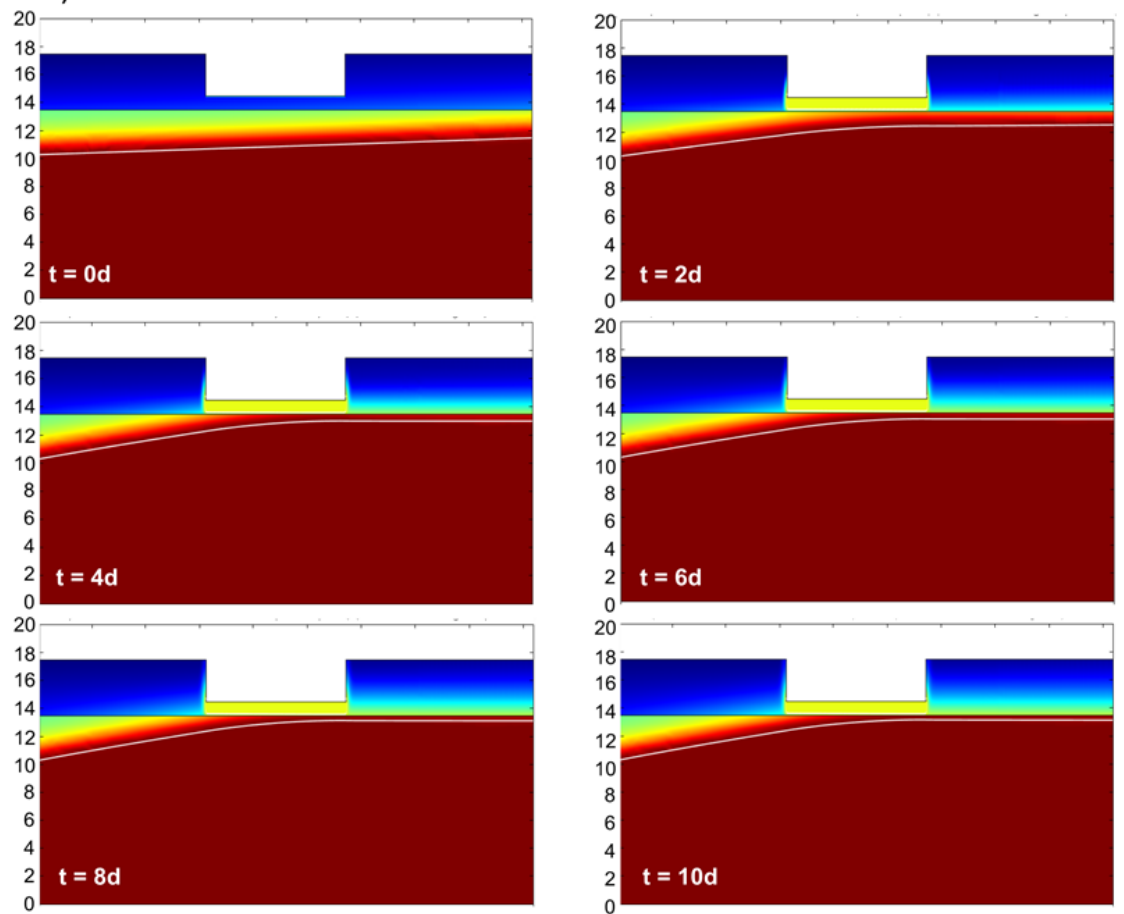

$\begin{array}{llllll}0.3 & 0.25 & 0.2 & 0.15 & 0.1 & 0.05\end{array}$

Fig. 7. Fitting of basin water level variations for $K_{s B}$ constant and $K_{s B}$ variable during infiltration experiments a) summer 2011 and b) winter 2011-2012, and c) modeled water content below the basin versus time for summer 2011.

The increases in saturated hydraulic conductivity, $K_{s B}$ are estimated at 1.80 and 1.44 of the initial value for summer 2001 and winter 2011-2012, respectively. Such increases can be compared to the prediction of the saturated hydraulic conductivity considering the change in temperature along the whole profile from initial temperature (equaled to groundwater temperature) to final temperature (equaled to surface temperature). Note that these assumptions on the field temperature seem more consistent for the case of summer 2011 for which warm water reached the piezometer M03 than for winter 2011-2012. For summer 2011 , the increase in temperature from $12^{\circ} \mathrm{C}$ to $24^{\circ} \mathrm{C}$ should have increased the hydraulic conductivity by a factor of 1.35 instead of 1.79 (Table 2). For winter 2011-2012, the decrease in temperature from $15^{\circ} \mathrm{C}$ down to $11^{\circ} \mathrm{C}$ should have reduced the hydraulic conductivity by a factor of 0.897 (Table 2 ), instead of the observed increase by a factor 1.44 . This gap between the evolution of hydraulic conductivity and the values predicted by considering the temperature shift was attributed to the effect of air entrapment since no additional process is expected. It is assumed that this gap quantifies the effect of air entrapment. Consequently, it is assumed that air entrapment explains approximately $43 \%$ of the increase in hydraulic conductivity for the infiltration experiment of summer 2011; while the increase in temperature explains the remaining 35\%. For winter 2011-2012, air-entrapment induces the augmentation of saturated hydraulic conductivity by an increase of $54 \%$ of its initial values, which compensates the decrease of $10 \%$ to temperature decrease in the soil profile.

The analysis of hydraulic conductivity versus time also gives information on the kinetics of processes (Table 2). For winter 2011-2012, the increase in hydraulic conductivity takes around 5 days to complete. Assuming that the dissolution of entrapped air is the main process for this increase, we can conclude that this process requires $\sim 5$ days. For summer 2011 , the increase in hydraulic conductivity also requires 5 days. But, both temperature increase and air-entrapment are involved for this experiment. Given the correspondence between the observed kinetics for summer 2011 and the kinetics of air dissolution in interstitial water, it is assumed that the warm up of water in the soil profile and its effects on water infiltration has similar kinetics. On the contrary, the global kinetics would have integrated two different kinetics, thus leading to a two-step increase over the 
whole duration of the experiment, which is inconsistent with observations (Fig. 5a). The hypothesis of similar kinetics, i.e. of a total of 5 days required to warm up the interstitial water along the soil profile is consistent with the arrival of warm water after 5-7 days at piezometer M030 (Fig. 6a). From these data, it is assumed that air entrapment will slow down water infiltration for $\sim 5$ days and that the effect of water temperature may appear after 5 days approximately for the case of the specifically studied site.

\section{CONCLUSIONS}

This study investigated water infiltration in an infiltration basin specifically used for groundwater recharge and for protecting the pumping well of Crépieux-Charmy (region of Lyon). Several infiltration experiments were conducted at the work scale to investigate the dependency of water infiltration on the contrast in temperature between the surface water and groundwater and on air-entrapment at the beginning of water infiltration. The experiments and modeling clearly demonstrated that both temperature-contrast and air-entrapment could significantly impact water infiltration. Water warm-up in the soil may increase the effective hydraulic conductivity of the soil and thus enhance water infiltration. In contrast, airentrapment may slow down water infiltration during the time necessary for its dissolution in the soil interstitial water; which may result in an increase in infiltration rate once air dissolution is completed. For both processes, the same period of five days is required to complete the increase in infiltration rate. Modeling allowed estimations of time evolution for effective saturated hydraulic conductivity and by this means the relative contributions of air-entrapment and temperature-contrast to the global effect. This was particularly interesting for the infiltration experiment during which both processes occurred. It was demonstrated that the effects of air-entrapment and temperaturecontrast were similar in magnitude.

The proposed modeling approach was based on the modelling of flow in unsaturated/saturated medium using Richards' equation, which assumes that flow is isotherm and which doesn't account for the dynamics of air phase (e.g. dissolution). This approach was proposed on purpose. The numerical resolution of Richards' equation is readily available for many practitioners and easy to compute for operation purposes. In addition, the consideration of non-isothermal flow, air compression and air dissolution increases model complexity and requires an important number of parameters to be estimated, which may render the approach unreliable. Similarly, the use of preferential flow model requires numerous experimentations and measures, rendering these models quite complex to use (Šimůnek et al., 2003). For the present case, our approach was to choose a model as simple as possible and to lump together the effects of temperature-contrast and air-compression in one parameter, namely the soil saturated hydraulic conductivity.

The results and conclusions of this study give important information for the management of infiltration basins. It clearly demonstrates that air-entrapment and temperature-contrast must be considered for the evaluation of infiltration rate. Indeed, the decision to clean or replace the sandy layer embedded in infiltration basins is made on the basis of the time-evolution of infiltration rate. However, miss-estimations of infiltration rates may be obtained if the effects of air-entrapment or temperaturecontrast are not considered. A short-term decrease in infiltration rate does not necessarily indicate clogging but may result from air-entrapment or temperature effects. From these results, it may be recommended (i) to measure infiltration rates after long enough to wait for steady state and (ii) to determine soil permittivity instead of hydraulic conductivity or infiltration rate that are impacted by the viscosity-temperature dependency.

This study also provides a methodology for testing other infiltration basins. It was clearly demonstrated that the association of several infiltration experiments could help in identifying processes and the impacts of air-entrapment and temperaturecontrast on water infiltration. In particular, it may be recommended to combine the following water infiltration experiments: (i) control experiment ensuring no temperature-contrast and no air-entrapment (for instance in spring with previous injection of large amounts of water to saturate the soil), (ii) infiltration experiment with only air entrapment (in spring to avoid temperature contrasts between surface water and groundwater and following a long dry period), (iii) infiltration experiment with only temperature contrast (in summer or winter with the injection of warm or cold water into a soil initially saturated), and (iv) infiltration experiments with both effects of temperature-contrast and air-entrapment (in winter or summer after a long dry period). These experiments are easy to conduct and require only to stop basin filling during enough time for experiments of types (ii) and (iv) and to proceed to water infiltration during summer or winter for experiments of types (iii) and (iv). Besides, numerical modeling can be used to quantify the relative contribution of temperature-contrast or airentrapment, as detailed in this study.

Despite the input of this study, several aspects need to be investigated more deeply. In this study, thermal effects and air dissolution were investigated at the work scale and investigations did not account for the complexity of flow processes (e.g. preferential flow in heterogeneous soils) and their coupling with heat transfer. In fact, both water and solid phases may conduct heat meaning that heat transfer may be much more complex than considered in this study (Vogel et al., 2011; Votrubová et al., 2012). During summer or winter seasons, the soil may exhibit an important vertical temperature gradient due to very hot or cold temperatures, respectively (Hillel, 1998). Further investigations are thus needed to properly characterize heat transfer accounting for heat conductance by both fluid and solid phases. Similarly, air compression and consequences on flow were simplified. Twophase flow mechanisms may be more complex with disconnected water or air phases (Joekar-Niasar et al., 2013; Marinas et al., 2009). A more detailed description of air dissolution into water along with a proper description of twophase flow accounting for the air and water connectivity may be required. In addition, flow in the vadose zone can be impacted by preferential flow (Köhne et al., 2009a, 2009b), and preferential flow was already pointed out by previous studies in similar sedimentary deposits (Goutaland et al., 2013; Winiarski et al., 2013). As for heat transfer, further investigations are needed to better understand water and air flows along with air compression/dissolution in the soil.

Acknowledgements. The authors wish to thanks ANRT and Veolia Environnement Recherche et Innovation for supporting this thesis work. This project is realized in collaboration with Veolia Water and the financial support of Grand Lyon urban community.

\section{REFERENCES}

Al-Muttair, F.F., Al-Turbak, A.S., 1991. Modeling of infiltration from an artificial recharge basin with a decreasing ponded depth. J. King Saud Univ. Eng. Sci., 3, 89-100. 
Bouwer, H., 1999. Artificial recharge of groundwater: systems, design, and management. In: Hydraulic Design Handbook. Larry W. Mays, New York.

Bouwer, H., 2002. Artificial recharge of groundwater: hydrogeology and engineering. Hydrogeol. J., 10, 121-142. DOI: 10.1007/s10040-001-0182-4.

Braud, I., Dantas-Antonino, A.C., Vauclin, M., Thony, J.L., Ruelle, P., 1995. A simple soil-plant-atmosphere transfer model (SiSPAT) development and field verification. J. Hydrol., 166, 213-250.

Constantz, J., 1982. Temperature dependence of unsaturated hydraulic conductivity of two soils. Soil Sci. Soc. Am. J., 46, 466-470.

Constantz, J., Thomas, C.L., Zellweger, G., 1994. Influence of diurnal variations in stream temperature on streamflow loss and groundwater recharge. Water Resour. Res., 30, 3253 3264.

Di Prima, S., Lassabatere, L., Bagarello, V., Iovino, M., Angulo-Jaramillo, R., 2016. Testing a new automated single ring infiltrometer for Beerkan infiltration experiments. Geoderma, 262, 20-34. http://dx.doi.org/10.1016/j.geoderma.2015.08.006

Dohnal, M., Jelinkova, V., Snehota, M., Dusek, J., Brezina, J., 2013. Tree-dimensional numerical analysis of water flow affected by entrapped air: Application of noninvasive imaging techniques. Vadose Zone J., 12. DOI: 10.2136/vzj2012.0078.

Faybishenko, B.A., 1995. Hydraulic behavior of quasi-saturated soils in the presence of entrapped air: laboratory experiments. Water Resour. Res., 31, 2421-2435. DOI: 10.1029/95WR01654.

Gette-Bouvarot, M., Mermillod-Blondin, F., Angulo-Jaramillo, R., Delolme, C., Lemoine, D., Lassabatere, L., Loizeau, S., Volatier, L., 2014. Coupling hydraulic and biological measurements highlights the key influence of algal biofilm on infiltration basin performance. Ecohydrology, 7, 950-964.

Goutaland, D., Winiarski, T., Lassabatere, L., Dubé, J.S., Angulo-Jaramillo, R., 2013. Sedimentary and hydraulic characterization of a heterogeneous glaciofluvial deposit: Application to the modeling of unsaturated flow. Eng. Geol., 166, 127-139. http://dx.doi.org/10.1016/j.enggeo.2013.09.006

Greskowiak, J., Prommer, H., Massmann, G., Johnston, C.D., Nützmann, G., Pekdeger, A., 2005. The impact of variably saturated conditions on hydrogeochemical changes during artificial recharge of groundwater. Appl. Geochem., 20, 1409-1426. DOI: 10.1016/j.apgeochem.2005.03.002.

Haverkamp, R., Ross, P.J., Smettem, K.R.J., Parlange, J.Y., 1994. 3-Dimensional analysis of infiltration from the disc infiltrometer. 2. Physically-based infiltration equation. Water Resour. Res., 30, 2931-2935.

Heilweil, V.M., Solomon, D.K., Ortiz, G., 2009. Silt and gas accumulation beneath an artificial recharge spreading basin, Southwestern Utah, U.S.A. Boletin Geologico y Minero, 120, 185-196.

Hillel, D., 1998. Environmental Soil Physics: Fundamentals, Applications, and Environmental Considerations. Academic Press, San Diego, USA, $771 \mathrm{p}$.

Jaynes, D.B., 1990. Temperature variations effect on fieldmeasured infiltration. Soil Sci. Soc. Am. J., 54, 305-312.

Joekar-Niasar, V., Doster, F., Armstrong, R.T., Wildenschild, D., Celia, M.A., 2013. Trapping and hysteresis in two-phase flow in porous media: A pore-network study. Water Resour. Res., 49, 4244-4256. DOI:10.1002/wrcr.20313.

Kildsgaard, J., Engesgaard, P., 2001. Numerical analysis of biological clogging in two-dimensional sand box experi- ments. J. Contam. Hydrol., 50, 261-285. DOI: 10.1016/S0169-7722(01)00109-7.

Köhne, J.M., Köhne, S., Šimůnek, J., 2009a. A review of model applications for structured soils: a) Water flow and tracer transport. J. Contam. Hydrol., 104, 4-35.

Köhne, J.M., Köhne, S., Šimůnek, J., 2009b. A review of model applications for structured soils: b) Pesticide transport. J. Contam. Hydrol., 104, 36-60.

Lassabatere, L., Angulo-Jaramillo, R., Soria Ugalde, J.M., Cuenca, R., Braud, I., Haverkamp, R., 2006. Beerkan estimation of soil transfer parameters through infiltration experiments-BEST. Soil Sci. Soc. Am. J., 70, 521-532.

Lassabatere, L., Angulo-Jaramillo, R., Soria-Ugalde, J.M., Simunek, J., Haverkamp, R., 2009. Numerical evaluation of a set of analytical infiltration equations. Water Resour. Res., 45.

Lassabatere, L., Angulo-Jaramillo, R., Goutaland, D., Letellier, L., Gaudet, J.P., Winiarski, T., Delolme, C., 2010. Effect of the settlement of sediments on water infiltration in two urban infiltration basins. Geoderma, 156, 316-325. http://dx.doi.org/10.1016/j.geoderma.2010.02.031

Lin, C., Greenwald, D., Banin, A., 2003. Temperature dependence of infiltration rate during large scale water recharge into soils. Soil Sci. Soc. Am. J., 67, 487-493.

Loizeau, S., 2013. Amélioration de la compréhension des fonctionnements hydrodynamiques du champ captant de Crépieux-Charmy. [Improvement of the understanding of hydrodynamic functioning of the Crépeiux-Chamy well field]. Université de Grenoble, Grenoble, $220 \mathrm{p}$.

Marinas, M., Smith, J., Roy, J., 2009. The effects of disconnect entrapped air on hydraulic conductivity in the presence of water table fluctuations. In: AGU Spring Meeting Abstracts.

Michot, D., Benderitter, Y., Dorigny, A., Nicoullaud, B., King, D., Tabbagh, A., 2003. Spatial and temporal monitoring of soil water content with an irrigated corn crop cover using surface electrical resistivity tomography. Water Resour. Res., 39, 1138. DOI:10.1029/2002WR001581.

Mualem, Y., 1976. A new model for predicting the hydraulic conductivity of unsaturated porous media. Water Resour. Res., 12, 513-522.

Muskat, M., 1937. The Flow of Homogeneous Fluids Through Porous Media. Mac Graw Hill, New York.

Nasta, P., Lassabatere, L., Kandelous, M.M., Simunek, J., Angulo-Jaramillo, R., 2012. Analysis of the role of tortuosity and infiltration constants in the Beerkan method. Soil Sci. Soc. Am. J., 76, 1999-2005.

Okubo, T., Matsumoto, J., 1979. Effect of infiltration rate on biological clogging and water quality changes during artificial recharge. Water Resour. Res., 15, 1536-1542. DOI: 10.1029/WR015i006p01536.

Rai, S.N., Singh, R.N., 1985. Water table fluctuations in response to time varying recharge. (Proceedings of the Jerusalem Symposium Scientific Basis for Water Resources Management). IAHS Publ. no. 153. IAHS Press, Wallingford, pp. 287-294.

Richards, L.A., 1931. Capillary conduction of liquids through porous mediums. J. Appl. Phys., 1, 318-333. DOI: 10.1063/1.1745010.

Schuh, W.M., 1988. In-situ method for monitoring layered hydraulic impedance development during artificial recharge with turbid water. J. Hydrol., 101, 173-189. DOI: 10.1016/0022-1694(88)90034-0.

Schuh, W.M., 1990. Seasonal variation of clogging of an artificial recharge basin in a northern climate. J. Hydrol., 121, 193-215. DOI: 10.1016/0022-1694(90)90232-M. 
Seymour, R.M., 2000. Air entrapment and consolidation occurring with saturated hydraulic conductivity changes with intermittent wetting. Irrig. Sci., 20, 9-14.

Šimůnek, J., Jarvis, N.J., van Genuchten, M.T., Gärdenäs, A., 2003. Review and comparison of models for describing nonequilibrium and preferential flow and transport in the vadose zone. J. Hydrol., 272, 14-35.

Sněhota, M., Císlerová, M., Gao Amin, M.H., Hall, L.D., 2010. Tracing the entrapped air in heterogeneous soil by means of magnetic resonance imaging. Vadose Zone J., 9, 373-384. DOI: $10.2136 /$ vzj2009.0103.

Stephens, D.B., Hsu, K.-C., Prieksat, M.A., Ankeny, M.D., Blandford, N., Roth, T.L., Kelsey, J.A., Whitworth, J.R., 1998. A comparison of estimated and calculated effective porosity. Hydrogeol. J., 6, 156-165.

Tu, Y.-C., Ting, C.-S., Tsai, H.-T., Chen, J.-W., Lee, C.-H., 2011. Dynamic analysis of the infiltration rate of artificial recharge of groundwater: A case study of Wanglong Lake, Pingtung, Taiwan. Environ. Earth Sci., 63, 77-85. DOI: 10.1007/s12665-010-0670-8.

van Genuchten, M.T., 1980. A closed-form equation for predicting the hydraulic conductivity of unsaturated soils. Soil Sci. Soc. Am. J., 44, 892-898.

Vandenbohede, A., Van Houtte, E., 2012. Heat transport and temperature distribution during managed artificial recharge with surface ponds. J. Hydrol., 472-473, 77-89. DOI: 10.1016/j.jhydrol.2012.09.028.
Vogel, T., Dohnal, M., Votrubova, J., 2011. Modeling heat fluxes in macroporous soil under sparse young forest of temperate humid climate. J. Hydrol., 402, 367-376. DOI: 10.1016/j.jhydrol.2011.03.030.

Votrubová, J., Dohnal, M., Vogel, T., Tesař, M., 2012. On parameterization of heat conduction in coupled soil water and heat flow modelling. Soil Water Res. 7, 125-137.

Wangemann, S.G., Kohl, R.A., Molumeli, P.A., 2000. Infiltration and percolation influenced by antecedent soil water content and air entrapment. Trans. Am. Soc. Agric. Eng., 43, 1517-1523.

Winiarski, T., Lassabatere, L., Angulo-Jaramillo, R., Goutaland, D., 2013. Characterization of the heterogeneous flow and pollutant transfer in the unsaturated zone in the fluvio-glacial deposit. Procedia Environ. Sci., 19, 955-964. http://dx.doi.org/10.1016/j.proenv.2013.06.105

Yilmaz, D., Lassabatere, L., Angulo-Jaramillo, R., Deneele, D., Legret, M., 2010. Hydrodynamic characterization of basic oxygen furnace slag through an adapted BEST method. Vadose Zone J., 9, 107-116.

Yilmaz, D., Lassabatere, L., Deneele, D., Angulo-Jaramillo, R., Legret, M., 2013. Influence of carbonation on the microstructure and hydraulic properties of a basic oxygen furnace slag. Vadose Zone J., 12, 2.

Received 1 June 2016 Accepted 6 December 2016 